Check for updates

Cite this: RSC Adv., 2018, 8, 19171

Received 5th February 2018

Accepted 5th May 2018

DOI: $10.1039 / c 8 \mathrm{ra01129j}$

rsc.li/rsc-advances

\title{
Fabrication of low-density carbon-bonded carbon fiber composites with an Hf-based coating for high temperature applications
}

\author{
Lin Xu, (D)* Wenbing Yang, Zhen Fan, Xingchao Li, Wei Li, Yongzhong Song, \\ Zhihai Feng and Dahai Zhang*
}

A novel $\mathrm{Hf}$-based anti-oxidation coating has been prepared on the surface of low-density carbon-bonded carbon fiber composites (CBCFs). The coating exhibits a gradient transition structure, with mainly $\mathrm{HfB}_{2}$, $\mathrm{Hf}_{2} \mathrm{Si}$ and $\mathrm{SiC}$ ceramics. Oxyacetylene torch testing has been utilized to evaluate the ablation resistance under the condition ranging from $1.6 \mathrm{MW} \mathrm{m}^{-2}$ to $2.2 \mathrm{MW} \mathrm{m}^{-2}$ for $300 \mathrm{~s}$. The experimental results show that the as-prepared $\mathrm{Hf}$-based coating can effectively protect CBCFs under high-temperature oxidation conditions. The surface maximum temperature can reach $1616-2037^{\circ} \mathrm{C}$, and the mass ablation rates vary from $-3.5 \times 10^{-5} \mathrm{~g} \mathrm{~s}^{-1} \mathrm{~cm}^{-2}$ to $1.5 \times 10^{-5} \mathrm{~g} \mathrm{~s}^{-1} \mathrm{~cm}^{-2}$. The formation of a dense $\mathrm{SiO}_{2}$ glass layer embedded with $\mathrm{HfO}_{2}$ grains or particle accumulation in the $\mathrm{HfO}_{2}$ layer is responsible for the good ablation resistance.

\section{Introduction}

Thermal protection system (TPS) is one of the key technologies of aerospace vehicle design and development. A lot of manpower and financial resources have been invested in the development of high-performance and reliable thermal protection materials and structures for their use in space. ${ }^{1,2}$ In recent years, the development of a large number of new lowdensity materials has raised research interests in lightweight thermal protection materials such as phenolic impregnated carbon ablator (PICA), ${ }^{3,4}$ SIRCA, ${ }^{5,6}$ and toughened uni-piece fibrous reinforced oxidization-resistant composites (TUFROC). ${ }^{7-10}$ Specifically, TUFROC has become desirable due to its unique properties including lightweightedness, low thermal conductivity, high temperature stability and low cost. $^{9,10}$ TUFROC has a two-piece structure, with a treated carbonaceous cap, namely, refractory oxidation-resistant ceramic carbon insulation (ROCCI) and a fibrous insulation base, namely, toughened uni-piece fibrous insulation (TUFI)treated alumina-enhanced thermal barrier (AETB). ${ }^{7}$ In this study, we focused on one kind of ROCCI, that is, carbon-bonded carbon fiber composites (CBCFs).

CBCFs are typical porous carbon-carbon (C/C) composites with low densities of $0.1-0.5 \mathrm{~g} \mathrm{~cm}^{-3}$ and high open porosities over $70 \% .{ }^{11-13}$ They are thought to be desirable candidates for high-temperature heat insulation application $\mathrm{s}^{\mathbf{1 4 , 1 5}}$ and thermal insulation applications in aerospace ${ }^{\mathbf{1 3 , 1 6 , 1 7}}$ due to their unique

Science and Technology of Advanced Functional Composite Laboratory, Aerospace Research Institute of Materials and Technology, Beijing 100076, China. E-mail: xulinhit@126.com; zhangdahai2014@126.com properties such as lightweightedness, low thermal conductivity, and high temperature stability However, low mechanical properties and poor oxidation resistance limit the wide applications of monolithic CBCFs. Recently, many research studies have been carried out to solve these problems. ${ }^{18-23}$ Carbon nanotubes $(\mathrm{CNTs})^{19}$ and $\mathrm{SiC}$ nanowires $\left(\mathrm{SiC}_{\mathrm{NWs}}\right)^{22}$ have been used to improve the mechanical properties of CBCFs. Various Si-based coatings (including $\mathrm{MoSi}_{2}$ and $\left.\mathrm{TaSi}_{2}\right)^{24}$ and $\mathrm{Zr}$-based coatings (such as $\left.\mathrm{ZrB}_{2}\right)^{19,25}$ have been widely investigated as an attractive way to ameliorate CBCFs' antioxidant properties. Unfortunately, up to now, the effective temperature of the anti-oxidation method has been limited to $1700{ }^{\circ} \mathrm{C}$. To the best of our knowledge, reports on high or ultra-high temperature oxidation resistance of CBCFs are limited.

In this paper, a new type of Hf-based anti-oxidation coating was designed and prepared to protect CBCFs for use at high temperature. The microstructure and the oxidation behavior of the coated CBCF composites were analyzed and discussed in detail. The results showed that the as-prepared Hf-based antioxidation coating could protect CBCFs under aerobic conditions at a maximum temperature range of $\sim 1616^{\circ} \mathrm{C}$ to $2037^{\circ} \mathrm{C}$.

\section{Experimental}

\subsection{Preparation of CBCFs}

Rayon-based carbon fibers with $0.8 \mathrm{~mm}$ length were used to prepare CBCFs by dispersion and filtration technique. The details of the preparations were given in our previous study. ${ }^{18} \mathrm{In}$ the present study, to improve the mechanical properties of CBCFs, pyrolytic carbon (PyC) was deposited on the surface of carbon fibers through chemical vapor infiltration (CVI) at 

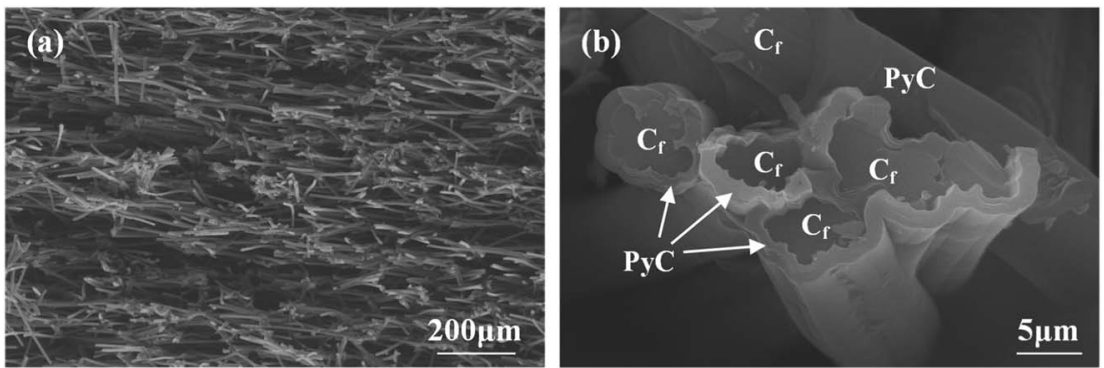

Fig. 1 SEM images of PyC-coated CBCFs after CVI: (a) low magnification; (b) high magnification in (a).

$1000{ }^{\circ} \mathrm{C}$ using propane as the carbon source. After deposition for $200 \mathrm{~h}$, the density of CBCFs increased from $0.25 \mathrm{~g} \mathrm{~cm}^{-3}$ to $0.36 \mathrm{~g} \mathrm{~cm}^{-3}$, and the open porosity decreased from $85.7 \%$ to 79.4\%. Fig. 1 shows the microstructures of as-prepared CBCFs after the CVI process. The characteristics of the random distribution of fibers and the highly porous network did not change as compared to those before CVI (Fig. 1a). A uniform PyC layer with a thickness of about $1 \mu \mathrm{m}$ was formed on the surface of the carbon fibers, as shown in Fig. 1b.

\subsection{Preparation of high temperature Hf-based anti-oxidation coating on CBCFs}

Commercially available Hf powder $(1-3 \mu \mathrm{m}$, purity $99.5 \%$, Northwest Institute for Non-ferrous Metal Research, China), Si powder (1-2 $\mu \mathrm{m}$, purity $99.9 \%$, Weifang Kaihua Micro-powder Co. Ltd., China), B (1-2 $\mu \mathrm{m}$, purity $99.5 \%$, Alfa Aesar (China) Chemicals Co. Ltd.) were used in this study.

The cylindrical samples $(\Phi 25.4 \times 8 \mathrm{~mm})$ used as substrates were cut from PyC-coated CBCFs. The samples were cleaned ultrasonically with ethanol and dried at $120^{\circ} \mathrm{C}$ for $2 \mathrm{~h}$. The Hfbased anti-oxidation coating was prepared by a simple SIR method, namely, slurry brushing, followed by infiltration processing and reactive sintering. The powdered mixtures of $\mathrm{Hf}$ (80 wt\%), Si (15 wt\%) and B (5 wt\%) were ball-milled for $10 \mathrm{~h}$. After mixing, the mixtures were added to a silicon resin to form a mixed slurry. Then, the Hf-based anti-oxidation coating was prepared by slurry brushing and infiltration processing using the above-mentioned mixed slurry. After drying at $200{ }^{\circ} \mathrm{C}$ for $2 \mathrm{~h}$, the impregnated samples were sintered at $1550{ }^{\circ} \mathrm{C}$ for $120 \mathrm{~min}$ in a high-temperature vacuum furnace. The thickness of this infiltration layer was controlled by changing the brush and pyrolysis cycles, which was different to the processes used in vacuum slurry infiltration methods. ${ }^{26}$

\subsection{Ablation tests and characterization}

The ablation behaviors of the as-prepared CBCFs with the Hfbased oxidation coating were evaluated under simulated atmospheric conditions using an oxyacetylene torch. Cylindrical-shaped samples with a size of $\phi 25.4 \mathrm{~mm} \times 8 \mathrm{~mm}$ were used in this study. The as-prepared CBCFs with the Hfbased oxidation coating having these dimensions had a bulk density of $0.8 \mathrm{~g} \mathrm{~cm}^{-3}$. During the ablation test, a water-cooled Gardon gauge was used to calibrate the heat flux, and a two- color pyrometer was used to record the surface temperature. Three typical ablation conditions were chosen by adjusting the ratio of acetylene to oxygen, i.e., $0.6: 0.4,0.7: 0.4$ and $0.8: 0.5$, as shown in Table 1; the corresponding heat fluxes and testing samples were 1.6 $\mathrm{MW} \mathrm{m}^{-2}(\mathrm{~S} 1), 1.8 \mathrm{MW} \mathrm{m}^{-2}$ (S2) and $2.2 \mathrm{MW}$ $\mathrm{m}^{-2}$ (S3). The distance from the nozzle tip of the oxyacetylene gun to the samples was about $40 \mathrm{~mm}$. The exposure time was $300 \mathrm{~s}$. The mass ablation rates were calculated by the following formula:

$$
R_{\mathrm{m}}=\frac{m_{0}-m_{1}}{s t}
$$

Here, $R_{\mathrm{m}}$ is the mass ablation rate; $m_{0}$ and $m_{1}$ are the masses of the samples before and after ablation, respectively; $s$ is the ablation area of the surface and $t$ is the ablation time.

The positive values of $R_{\mathrm{m}}$ represent weight losses, and negative values represent weight gains.

The phase composition was determined via X-ray diffraction using $\mathrm{Cu} \mathrm{K} \alpha$ radiation. Surface and cross-sectional morphologies of the coatings before and after the ablation tests were observed using scanning electron microscopy (SEM) with simultaneous chemical analysis by energy dispersive spectroscopy (EDS).

\section{Results and discussion}

\subsection{Microstructure of the as-prepared Hf-based coated CBCFs}

The morphology of the prepared Hf-based surface coating is displayed in Fig. 2. As shown in Fig. 2a, the surface coating exhibits a typical rough structure without the formation of macro-cracks, which demonstrates the physical compatibility of the coating with CBCFs. The details corresponding to elemental distribution maps are shown in Fig. $2 \mathrm{~b}-\mathrm{e}$, which exhibit the uniform dispersions of Hf, Si, B and C. Fig. 3 shows the surface

Table 1 Ablation properties of CBCFs with the Hf-based oxidation coating for $300 \mathrm{~s}$

\begin{tabular}{llllll}
\hline Samples & $\mathrm{O}_{2}: \mathrm{C}_{2} \mathrm{H}_{2}$ & $\mathrm{H}\left(\mathrm{MW} \mathrm{m}^{-2}\right)$ & $t(\mathrm{~s})$ & $T_{\max }\left({ }^{\circ} \mathrm{C}\right)$ & $R_{\mathrm{m}}\left(\mathrm{g} \mathrm{cm}^{-2} \mathrm{~s}^{-1}\right)$ \\
\hline S1 & $0.6: 0.4$ & 1.6 & 300 & 1616 & $-3.5 \times 10^{-5}$ \\
S2 & $0.7: 0.4$ & 1.8 & 300 & 1830 & $-1.7 \times 10^{-5}$ \\
S3 & $0.8: 0.5$ & 2.2 & 300 & 2037 & $1.5 \times 10^{-5}$
\end{tabular}



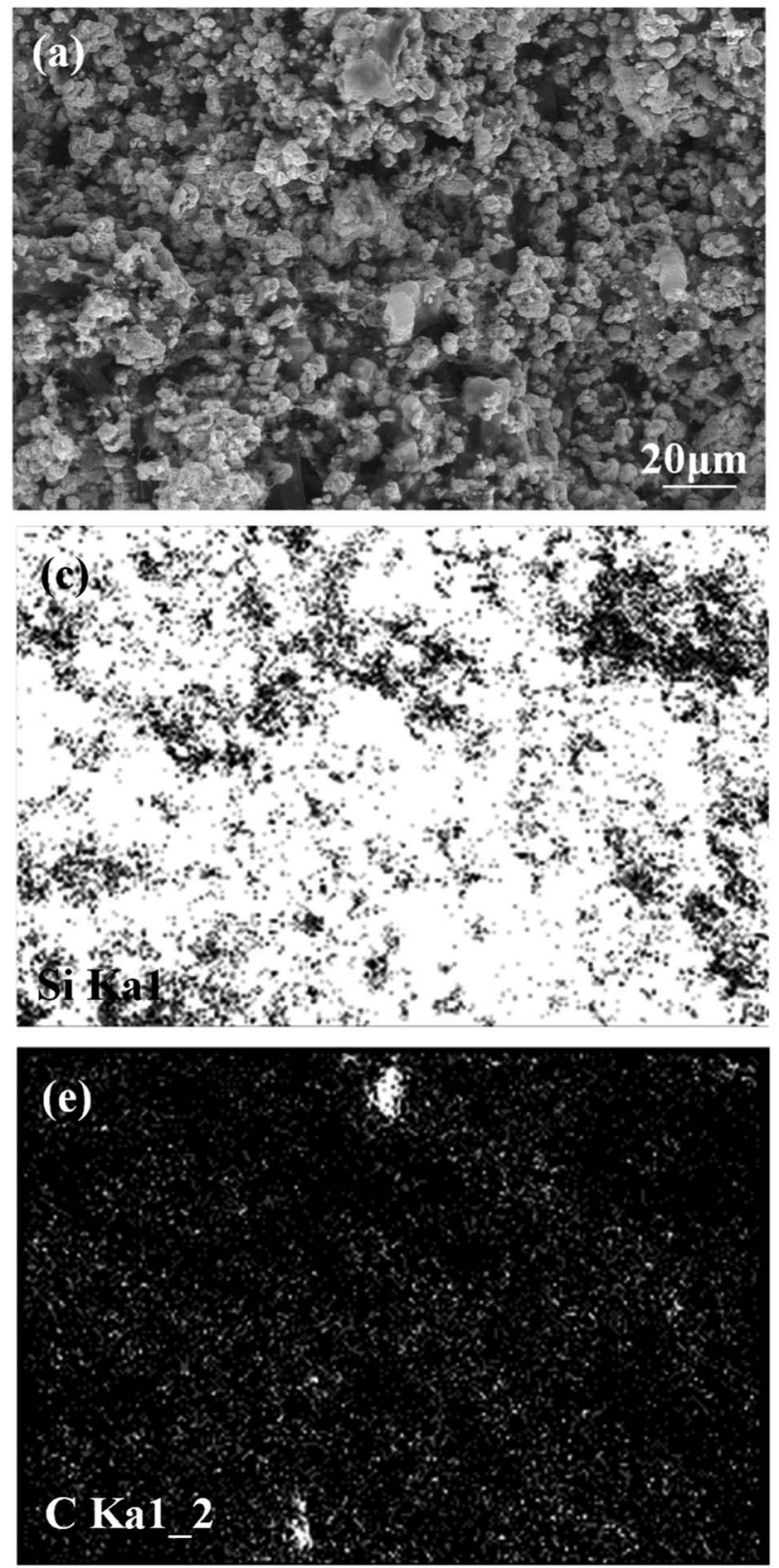

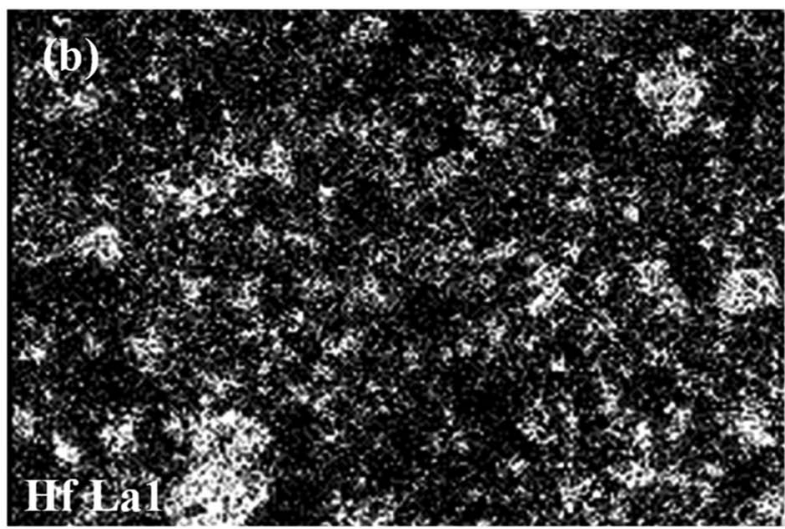

(d)

\section{B Ka1 2}

Fig. 2 SEM micrograph and the corresponding elemental distribution maps of Hf-based anti-oxidation coating: (a) SEM image; (b) Hf distribution; (c) Si distribution; (d) B distribution, (e) C distribution.

XRD results of the prepared Hf-based coating. Based on the diffraction peaks, the main phases in the coating are mainly $\mathrm{HfB}_{2}, \mathrm{Hf}_{2} \mathrm{Si}$ and SiC. A small amount of residual $\mathrm{Si}$ is also detected by XRD. The results indicate that most of the impregnated ceramic powders have reacted in situ with each other or with carbon to form the $\mathrm{HfB}_{2}-\mathrm{Hf}_{2} \mathrm{Si}-\mathrm{SiC}$ coating, which can afford good oxidation protection under high temperature..$^{27,28}$

Fig. 4 displays the cross-sectional morphologies of the asprepared Hf-based anti-oxidation coating. It can be found that the oxidation coating is about $300 \mu \mathrm{m}$ in thickness, and there are no clear penetration cracks between the oxidation coating layer and CBCFs, revealing good compatibility between the layers (Fig. 4a). Moreover, as shown in Fig. 4b and c, two oxidation layers can be found: an inner layer with a porous structure ( $\sim 600 \mu \mathrm{m}$ in thickness) and an outer layer with a more compact structure at the top of the coating layer $(\sim 100 \mu \mathrm{m}$ in thickness). The main phases including white $\mathrm{HfB}_{2}$ and $\mathrm{Hf}_{2} \mathrm{Si}$ (marked as $\mathrm{H}$ ) and gray $\mathrm{SiC}$ (marked as $\mathrm{S}$ ) are dispersed homogenously in the outer coating (Fig. 4b). The Hf-based antioxidation coating can penetrate into CBCFs to form an inner layer with porous carbon fiber embedded within the white Hfbased phase and gray SiC phase; the carbon fibers are marked as $C_{\mathrm{f}}$ and the pores are marked as $\mathrm{P}$ (Fig. 4c). Thus, the results clearly reveal that a gradient structure oxidation layer can be prepared using this SIR processing in the present study, which 


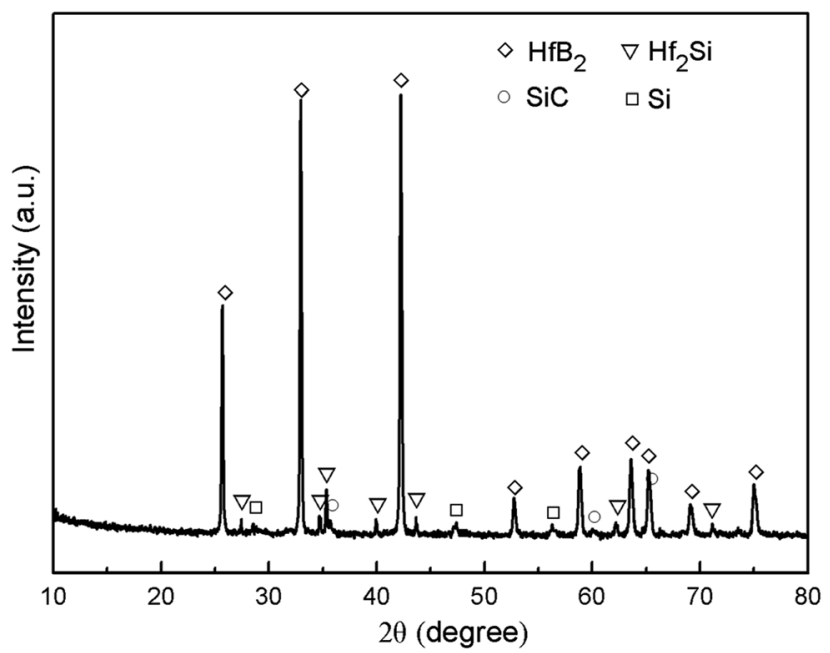

Fig. 3 XRD pattern of the prepared coating.

is beneficial to enhance the impact resistance and the thermal expansion matching between the coating and CBCFs, which is similar to the observations for the TUFI coating of ROCCI., Meanwhile, it is clear that the carbon fibers are covered with a thin layer of PyC, as shown in Fig. 4d, which is beneficial to improve the mechanical properties since it increases preform stiffness and prevents damage to the carbon fibers in the SIR processing. ${ }^{20}$ In the present study, with the introduction of PyC interface, the compressive strength is improved from $0.22 \mathrm{MPa}$ to $0.97 \mathrm{MPa}$, with a $341 \%$ improvement as compared with that for the original CBCFs.

\subsection{Ablation properties of CBCFs with the Hf-based coating}

The ablation test results are summarized in Table 1, illustrating the maximum surface temperatures of $\mathrm{S} 1, \mathrm{~S} 2$ and $\mathrm{S} 3$ as $1616^{\circ} \mathrm{C}$, $1830{ }^{\circ} \mathrm{C}$ and $2037{ }^{\circ} \mathrm{C}$, respectively. This indicates that the surface temperature increases monotonously with the heat flux from 1.6 $\mathrm{MW} \mathrm{m}^{-2}$ to $1.8 \mathrm{MW} \mathrm{m}^{-2}$ and $2.2 \mathrm{MW} \mathrm{m}^{-2}$. At the same total exposure time of $300 \mathrm{~s}$, the mass ablation rates vary from $-3.5 \times 10^{-5} \mathrm{~g} \mathrm{~s}^{-1} \mathrm{~cm}^{-2}$ (S1) to $-1.7 \times 10^{-5} \mathrm{~g} \mathrm{~s}^{-1} \mathrm{~cm}^{-2}$ (S2) and then to $1.5 \times 10^{-5} \mathrm{~g} \mathrm{~s}^{-1} \mathrm{~cm}^{-2}$ (S3), and they increase with the heat flux. Meanwhile, clearly, the thicknesses of all samples did not change.

Time-surface temperature data under different heat flux conditions are shown in Fig. 5. The macrographs of the coated samples after ablation are shown in Fig. 6. The un-ablated surface is compact and gray in color (Fig. 6a). After ablation at 1.6 $\mathrm{MW} \mathrm{m}^{-2}$, the coated surface turns black with many glassy oxidation products, as shown in Fig. 6b. During the whole ablation process of $300 \mathrm{~s}$, the oxidizing reaction on the surface tends to be steady, and the temperature is also steady at around $1600{ }^{\circ} \mathrm{C}$ (Fig. 5). However, when the ablation heat flux increases to $1.8 \mathrm{MW} \mathrm{m}^{-2}$, the surface temperature of the ablation center region rapidly reaches about $1700{ }^{\circ} \mathrm{C}$ and remains stable for about $250 \mathrm{~s}$, followed by a slow increase to a maximum temperature of $1830{ }^{\circ} \mathrm{C}$, as shown in Fig. 5. At this high temperature condition, an oxidation surface mixture with black
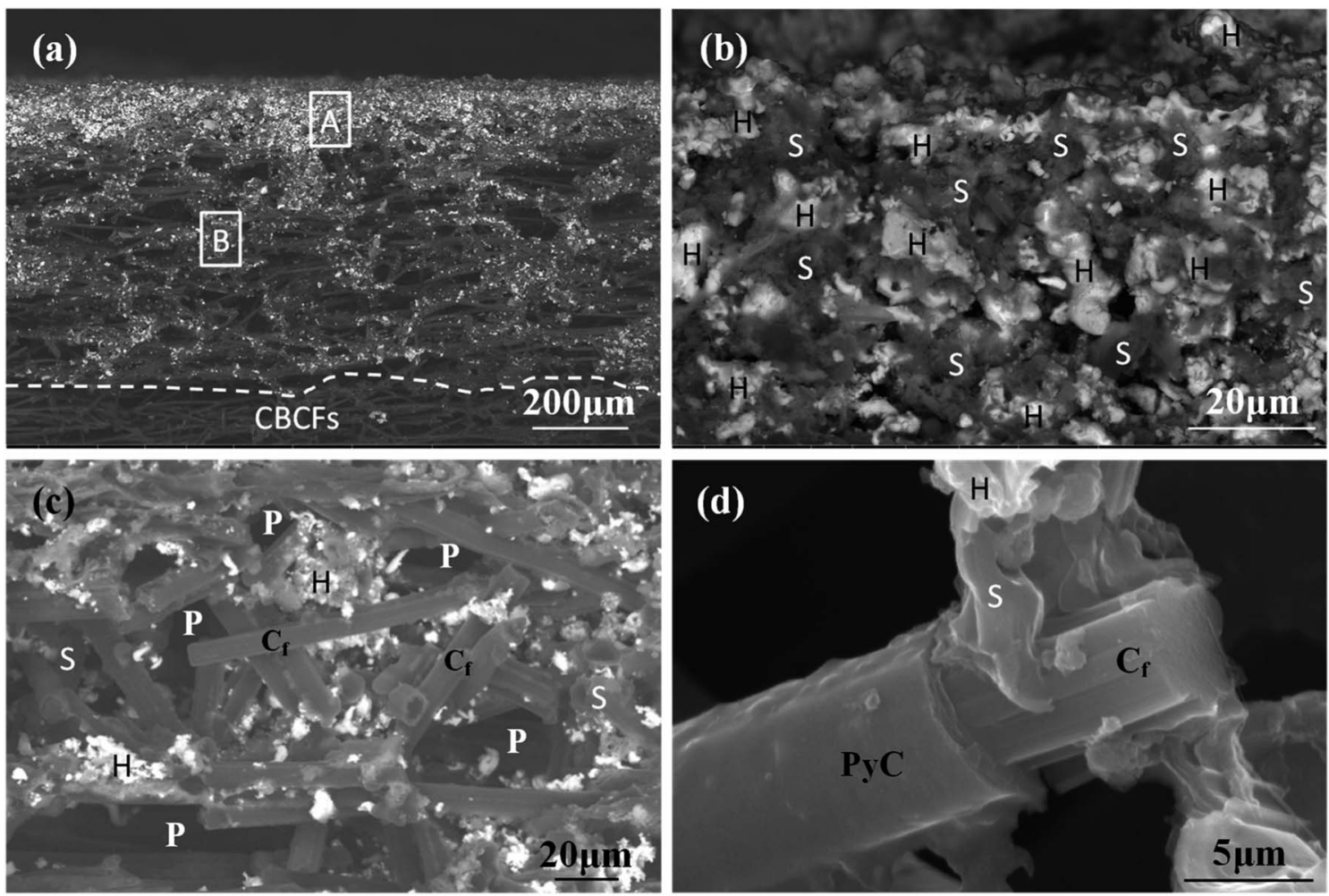

Fig. 4 Cross-sectional SEM images of the prepared coatings: (a) low magnification; (b) and (c) high magnification corresponding to regions A and $B$ in (a), respectively; (d) high magnification of (c). 


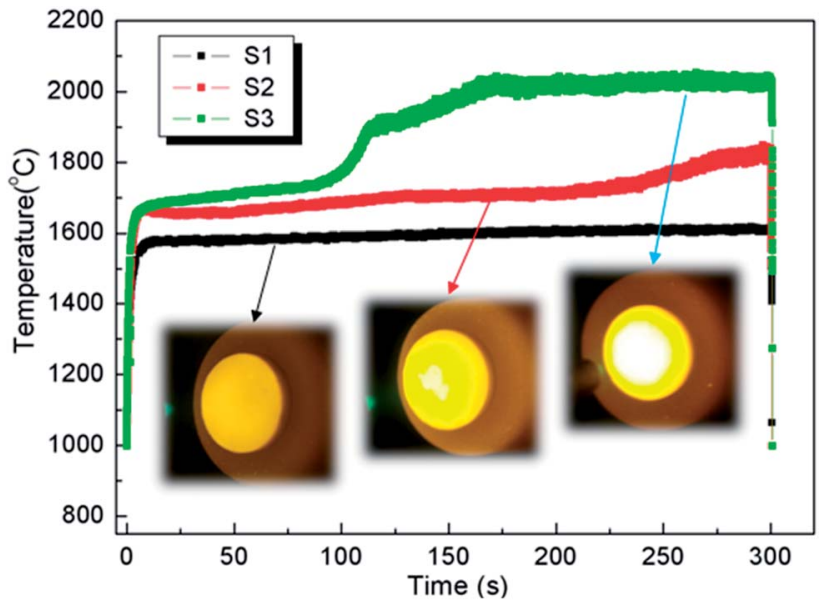

Fig. 5 Surface temperatures measured during ablation testing for different samples.

and white phases is formed on the surface of S2 (Fig. 6c). When the heat flux further increases to $2.2 \mathrm{MW} \mathrm{m}^{-2}$, the temperature rapidly reaches around $1730{ }^{\circ} \mathrm{C}$ and then, it further increases to $2037{ }^{\circ} \mathrm{C}$ at $170 \mathrm{~s}$ and remains steady for the last $130 \mathrm{~s}$. During this condition, more white oxidation products can be found on the surface of S3, as shown in Fig. 6d. All the CBCF samples with Hf-based coatings appear without cracks and spallation on the surface during the test. It should be pointed out that according to Fig. 5, temperature jump phenomena are detected for $\mathrm{S} 2$ and S3 probably due to the formation of white products, which is different from the observations for $\mathrm{C} / \mathrm{SiC}$ and $\mathrm{C} / \mathrm{SiC}-\mathrm{HfC}$ composites. ${ }^{28,29}$ Additional experimental verification including theoretical analysis is needed to explain the temperature jump phenomenon of Hf-based CBCFs under an oxidation environment.

\subsection{Microstructure evolution of CBCFs with the Hf-based coating after ablation}

Fig. 7 exhibits the XRD patterns of CBCFs with the Hf-based coatings after ablation testing. Different phases were formed under different heat fluxes at the same exposure time. It was clear that the identified phases on the surface of S1 were composed of $\mathrm{HfB}_{2}, \mathrm{Hf}_{2} \mathrm{Si}$ and $\mathrm{SiC}$ from the original coating as well as the new phase of $\mathrm{SiO}_{2}$, as shown in Fig. 7a. When the

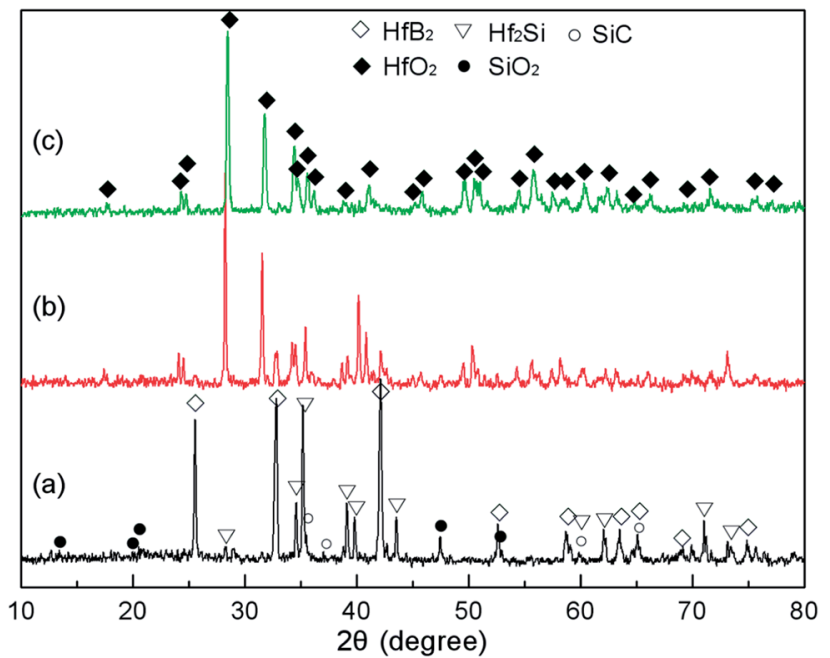

Fig. 7 XRD patterns of different CBCFs with the $\mathrm{Hf}$-based oxidation coating after ablation for 300 s: (a) S1; (b) S2; (c) S3.

maximum surface temperature increased up to $1830{ }^{\circ} \mathrm{C}$, the peaks were mainly of $\mathrm{HfO}_{2}$ and $\mathrm{SiO}_{2}$ along with those corresponding to small amounts of $\mathrm{HfB}_{2}$ and $\mathrm{Hf}_{2} \mathrm{Si}$, implying that the oxidation coating of S2 was partly oxidized (Fig. 7b). When the surface temperature further increased up to $2037{ }^{\circ} \mathrm{C}$, it was found that only $\mathrm{HfO}_{2}$ was present, indicating that the surface of S3 was completely oxidized (Fig. 7c), and these results were in good accordance with the results of macrograph analysis (Fig. 6d).

To further understand the ablation behaviors of different samples, the evolution of surface microstructure has been investigated. As shown in Fig. 8, the oxidized surface of S1 was covered with a dense gray glassy layer embedded within a white phase. According to EDS and XRD analyses (Fig. 7 and 8), the gray glassy layer was $\mathrm{SiO}_{2}$, and the white phase was composed of $\mathrm{Hf}, \mathrm{O}$ and $\mathrm{Si}$, which might have been $\mathrm{HfO}_{2}$ oxide grains covered with an amorphous silica layer. The element Ir was detected from the surface spray process of SEM analysis. In addition, no clear cracks were found on the surface due to the crack-sealing function of the glassy phase, which could prevent the oxygen diffusion and protect the layers beneath.

As indicated in Fig. 9, there are two typical ablation regions on the surface of S2: the brim ablation region and the ablation center region. The brim ablation region was covered with a gray
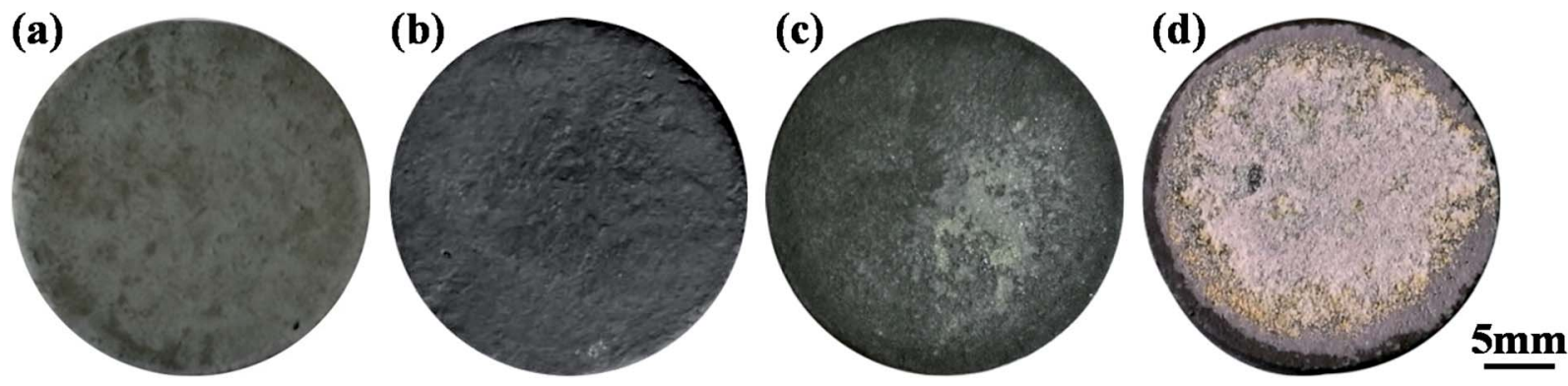

Fig. 6 Macro-photographs of CBCFs with the Hf-based oxidation coating before and after the ablation test for $300 \mathrm{~s}$ : (a) before ablation; (b) after ablation of S1; (c) after ablation of S2; (d) after ablation of S3. 

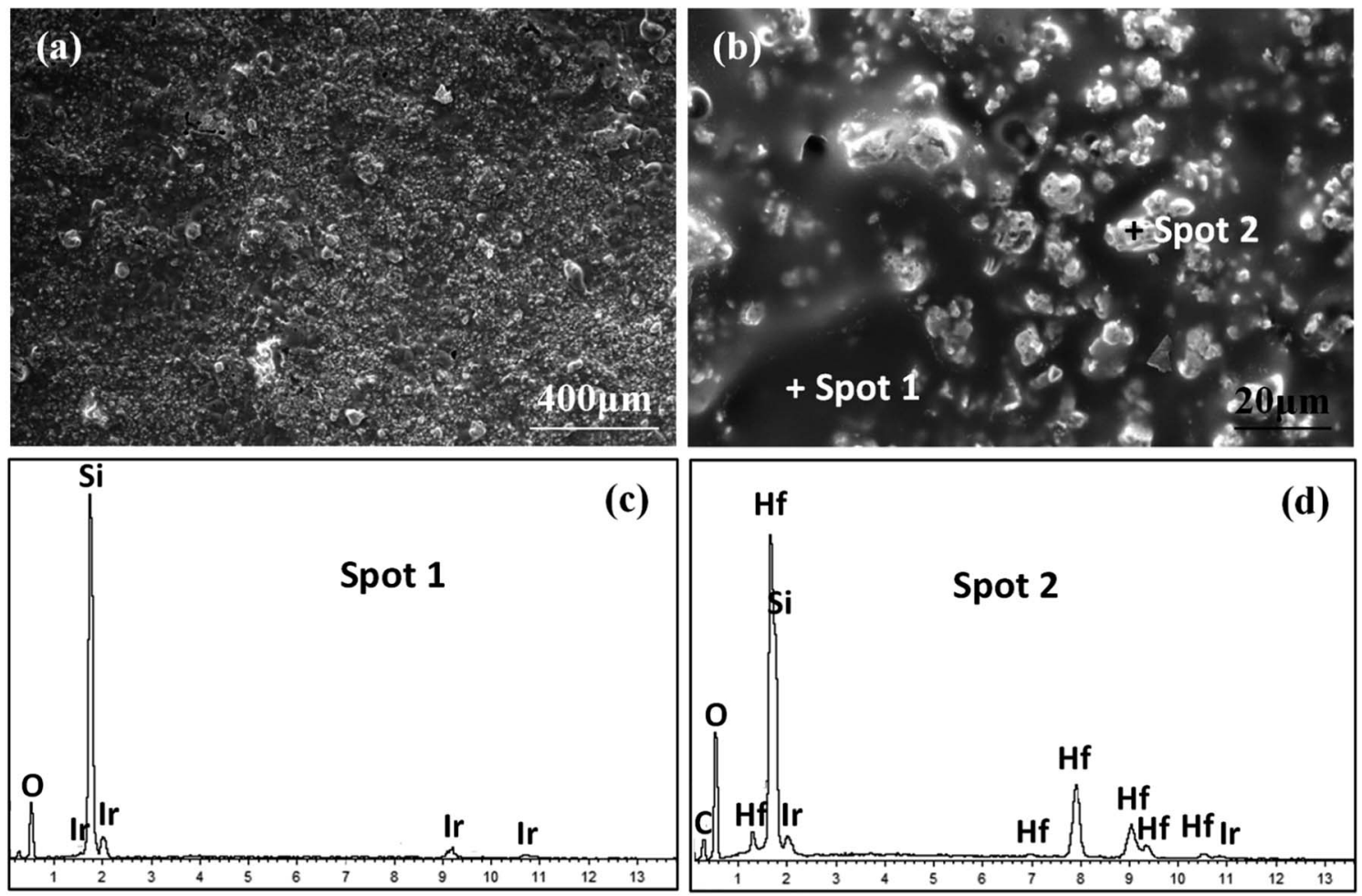

Fig. 8 Surface morphologies of S1 after ablation for 300 s: (a) low magnification; (b) high magnification of (a); (c) and (d) EDS patterns corresponding to spot 1 and spot 2 in (b), respectively.
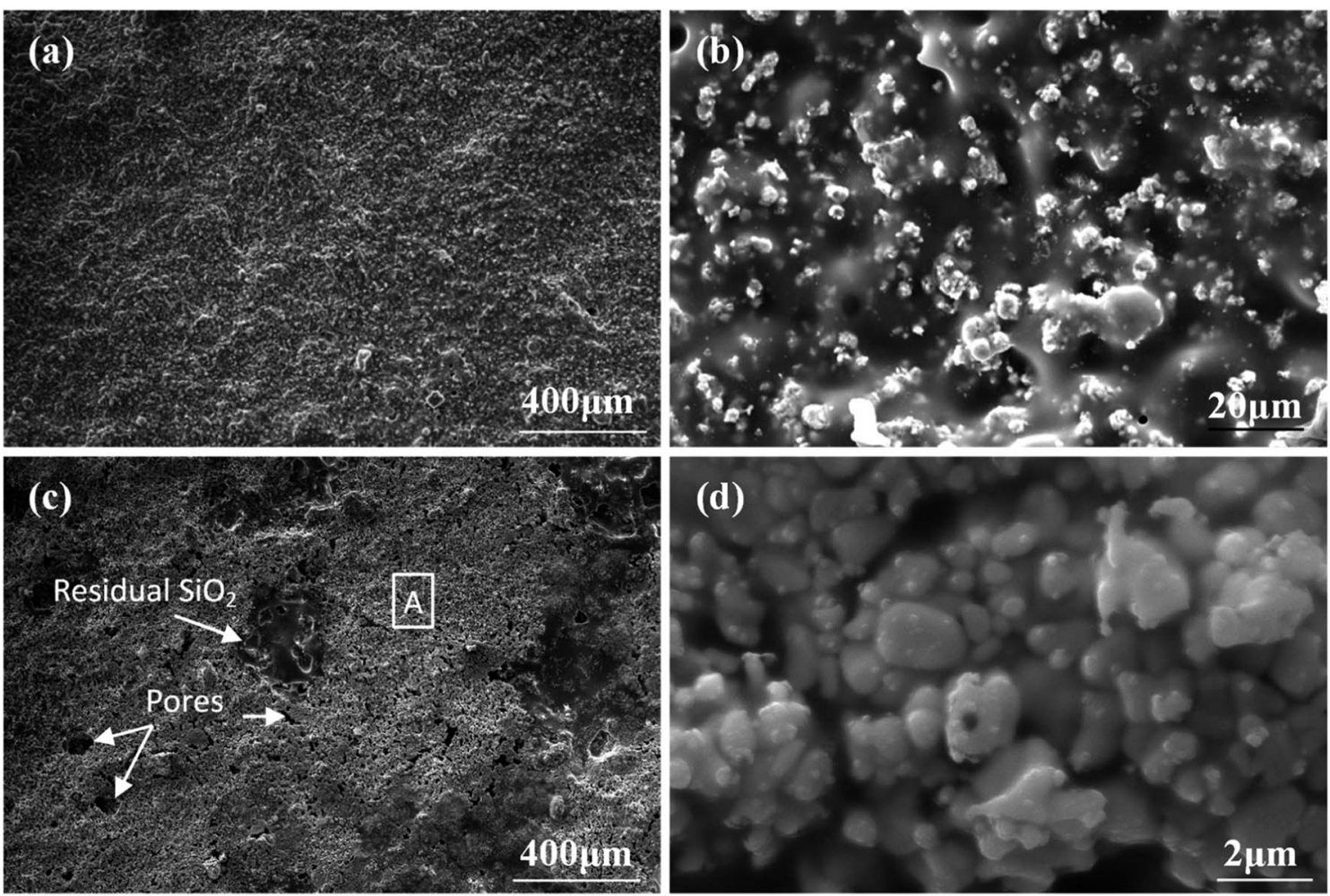

Fig. 9 Surface morphologies of S2 after oxyacetylene test for 300 s: (a) low magnification of the brim region; (b) high magnification of (a); (c) low magnification of the ablation center region; (d) high magnification corresponding to region $\mathrm{A}$ in (c). 
coating embedded within the white phase similar to the observations for the surface of S1 (Fig. 9a and b), which meant that both samples experienced equivalent environments. According to literature,$^{30}$ the temperature of the ablation center region is much higher than that of the brim ablation region under the vertically jetted flowing oxyacetylene torch testing environment. When the maximum temperature was increased to $1830{ }^{\circ} \mathrm{C}$ in the ablation center region, the vapor pressure of $\mathrm{SiO}_{2}$ increased substantially, ${ }^{31}$ leading to its evaporation; also, $\mathrm{SiO}_{2}$ was blown away due to the impact of oxyacetylene torch. Traces of gas volatilization were easily observed, and the ablation center zone was coated by a large number of fine $\mathrm{HfO}_{2}$ grains (about $0.5-2 \mu \mathrm{m}$ in size) with no exposed substrate, as shown in Fig. 9c and d.

SEM images of oxidized surfaces of S3 are presented in Fig. 10. The surface appeared similar to that of the ablation region of S2 but with a higher amount of $\mathrm{HfO}_{2}$ phase, which was confirmed by EDS. It should be noted that at such a high temperature (maximum being $2037^{\circ} \mathrm{C}$ ), in addition to the significant evaporation of $\mathrm{SiO}_{2}$ due to its low viscosity, the problem of the active oxidation of $\mathrm{SiC}$ was taken into consideration in the present study. The thermal stability of refractory carbide/boride composites in an oxidizing environment has been studied by Wang et al. ${ }^{32}$ The results confirmed that at a high temperature or a low oxygen partial pressure, $\mathrm{SiC}$ underwent a transition from passive to active oxidation, and the protective $\mathrm{SiO}_{2}$ layer was removed as $\mathrm{SiO}(\mathrm{g})$. Furthermore, two kinds of $\mathrm{HfO}_{2}$ phases were detected on the surface of ablated S3, as shown in Fig. 10. One consisted of fine $\mathrm{HfO}_{2}$ grains with an average size larger than that of the ablation region of S2, which was about $-5 \mu \mathrm{m}$ (Fig. 10c). The other was similar to molten $\mathrm{HfO}_{2}$ with a much larger size of over $10 \mu \mathrm{m}$ (Fig. 10b). Additionally, no carbon fibers were detected, indicating that the $\mathrm{HfO}_{2}$ layer could withstand the highspeed oxyacetylene torch flame and serve as an effective insulator to resist the high-temperature ablation.

\subsection{Ablation mechanism}

As shown in Fig. 11, a schematic diagram is used to explain the ablation mechanism of CBCFs with the Hf-based coating under different testing environments. During the ablation testing process, the coated CBCFs react with oxygen as follows: ${ }^{33-35}$

$$
\begin{aligned}
& \mathrm{HfB}_{2}(\mathrm{~s})+5 / 2 \mathrm{O}_{2}(\mathrm{~g})=\mathrm{HfO}_{2}(\mathrm{~s})+\mathrm{B}_{2} \mathrm{O}_{3}(\mathrm{l}) \\
& \mathrm{Hf}_{2} \mathrm{Si}(\mathrm{s})+3 \mathrm{O}_{2}(\mathrm{~g})=2 \mathrm{HfO}_{2}(\mathrm{~s})+\mathrm{SiO}_{2}(\mathrm{l}) \\
& \mathrm{SiC}(\mathrm{s})+ 3 / 2 \mathrm{O}_{2}(\mathrm{~g})=\mathrm{SiO}_{2}(\mathrm{l})+\mathrm{CO}(\mathrm{l}) \\
& \mathrm{B}_{2} \mathrm{O}_{3}(\mathrm{l})=\mathrm{B}_{2} \mathrm{O}_{3}(\mathrm{~g}) \\
& \mathrm{SiO}_{2}(\mathrm{~s})=\mathrm{SiO}_{2}(\mathrm{~g})
\end{aligned}
$$

When the ablation was started, the outer coating was exposed to the flame in the oxygen-rich environment. The surface temperature rose rapidly to the testing temperature
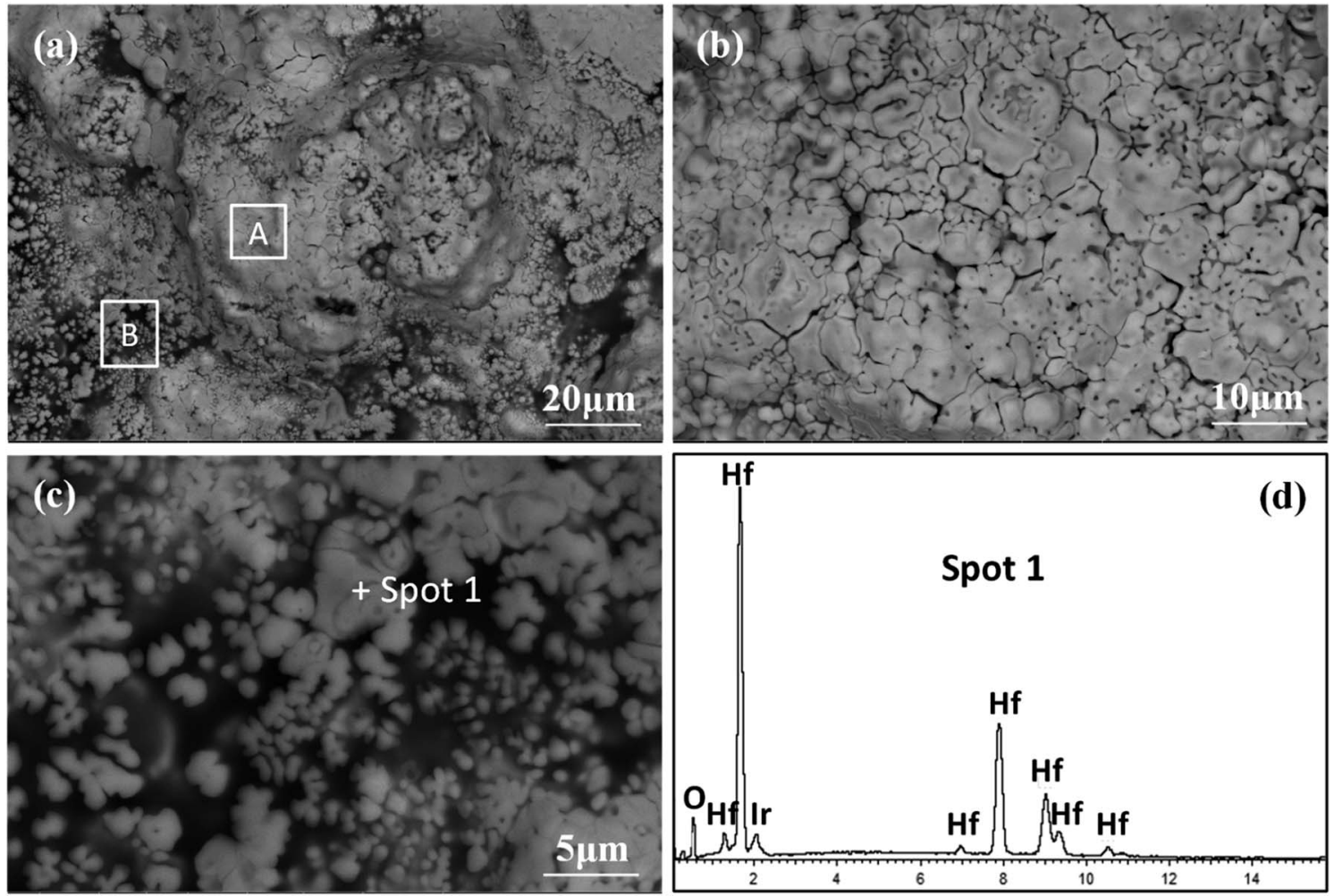

Fig. 10 Surface morphologies of S3 after oxyacetylene test for $300 \mathrm{~s}$ : (a) low magnification; (b) and (c) high magnification corresponding to regions $A$ and $B$ in (a), respectively; (d) EDS pattern corresponding to spot 1 in (c). 


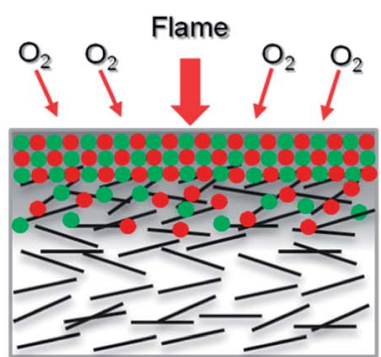

(a)

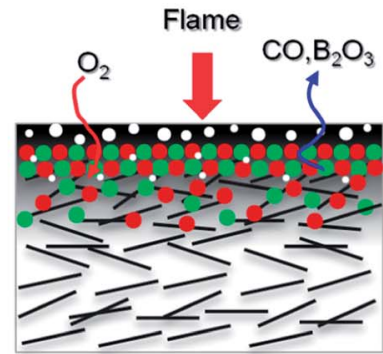

(b)

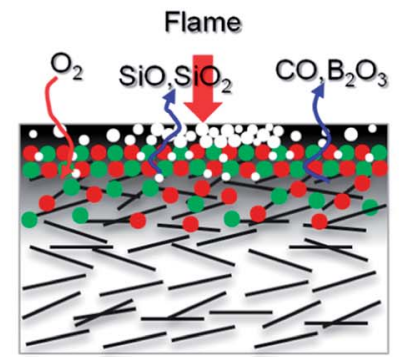

(c)

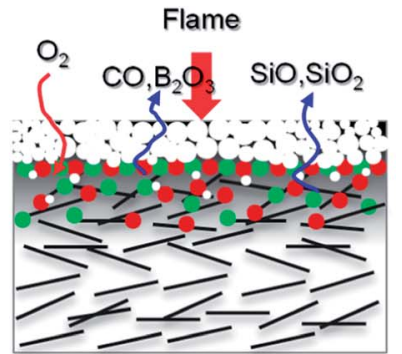

(d)

- $\mathrm{HfB}_{2}$ or $\mathrm{Hf}_{2} \mathrm{Si} \quad \mathrm{SiC}-\mathrm{C}_{\mathrm{f}}$

$\circ \mathrm{HfO}_{2}$

$\mathrm{SiO}_{2}$

Fig. 11 Schematic diagram for the ablation of CBCFs with the Hf-based coating: (a) initial stage of ablation; (b) S1; (c) S2; (d) S3.

within $10 \mathrm{~s}$ (Fig. 5). When the temperature approached $1600{ }^{\circ} \mathrm{C}$ for $\mathrm{S} 1, \mathrm{HfB}_{2}, \mathrm{Hf}_{2} \mathrm{Si}$ and $\mathrm{SiC}$ were quickly oxidized to form an oxidation layer on the surface of the coated CBCFs, according to Reactions (2)-(4). A gray glassy layer of $\mathrm{SiO}_{2}$ embedded within $\mathrm{HfO}_{2}$ was formed on the surface, as shown in Fig. 11b. No $\mathrm{B}_{2} \mathrm{O}_{3}$ was detected through XRD or EDS analysis; it must have vaporized in the testing environment due to its low melting point and high vapor pressure. ${ }^{36}$ In addition, there was no clear crack on the surface, which may be attributed to the possibility that the glassy phase effectively sealed the microcracks during ablation, and this could prevent the oxygen diffusion and protect the matrix beneath.

When the heat flux increase to $1.8 \mathrm{MW} \mathrm{m}^{-2}$ for $\mathrm{S} 2$, the $\mathrm{Hf}-$ based anti-oxidation coating underwent different ablation environments due to the different temperature distribution on the surface. At the low temperature condition in the brim zone, a protective glass layer was formed, and it acted as a barrier to prevent further diffusion of oxygen (Fig. 11c). However, at the high temperature condition in the ablation region, the efficiency of SiC significantly decreased due to its rapid evaporation and active oxidation, according to Reaction (6). Residual $\mathrm{SiO}_{2}$ and micropores were left after the evaporation of different gases such as $\mathrm{SiO}, \mathrm{SiO}_{2}, \mathrm{CO}$ and $\mathrm{B}_{2} \mathrm{O}_{3}$, as shown in Fig. 11c.

With the further increase of heat flux to $2.2 \mathrm{MW} \mathrm{m}^{-2}$ for $\mathrm{S} 3$, the coating was gradually oxidized, and the glass phases on the surface were completely evaporated leaving only $\mathrm{HfO}_{2}$, as shown in Fig. 11d. Therefore, a mass loss occurred in S3, which was different to the observations for S1 and S2 (Table 1). However, the surfaces of the composites were almost integrated, and they were fully covered with $\mathrm{HfO}_{2}$ grains. In addition, there were no bare fibers, which indicated the excellent oxidation protection of the as-prepared CBCFs with the Hf-based coating at 2.2 MW $\mathrm{m}^{-2}$ with the maximum temperature approaching $2037^{\circ} \mathrm{C}$ for $300 \mathrm{~s}$. Due to the complexity of the high temperature reaction and phase evolution, new fine detection techniques such as Raman spectroscopy, FESEM and TEM EDAX might be used in our future research..$^{37,38}$

\section{Conclusions}

In this study, a new type of Hf-based coating was designed and prepared to prevent the oxidation of CBCFs at high temperature. The as-prepared coating had a gradient transition structure, and it was about $300 \mu \mathrm{m}$ in thickness. No visible macrocracks were detected during the fabrication process and the high-temperature testing/cooling process, owing to the good performance of CBCFs with the Hf-based coating. The mass ablation rates of S1 and S2 were only $-3.5 \times 10^{-5} \mathrm{~g} \mathrm{~s}^{-1} \mathrm{~cm}^{-2}$ and $-1.7 \times 10^{-5} \mathrm{~g} \mathrm{~s}^{-1} \mathrm{~cm}^{-2}$ after $300 \mathrm{~s}$, with the maximum surface temperatures being $1616{ }^{\circ} \mathrm{C}$ and $1830{ }^{\circ} \mathrm{C}$, respectively. Meanwhile, the mass ablation rate of S3 was $1.5 \times 10^{-5} \mathrm{~g} \mathrm{~s}^{-1}$ $\mathrm{cm}^{-2}$ after ablation for $300 \mathrm{~s}$, with the maximum temperature approaching $2037^{\circ} \mathrm{C}$. Overall, the as-prepared Hf-based coating exhibited excellent ablation resistance to protect CBCFs. The results presented in this paper suggest that CBCFs with the Hfbased coating are important considerations for potential applications in future TPS, which requires lightweight, high performance and low cost materials.

\section{Conflicts of interest}

There are no conflicts to declare.

\section{Acknowledgements}

This study was finically supported by the National Basic Research Program of China (2015CB655200), the National Natural Science Foundation of China (51702076) and the Open Research Fund of Science and Technology on High Strength Structure Materials Laboratory.

\section{References}

1 D. E. Glass, Ceramic matrix composite (CMC) thermal protection systems (TPS) and hot structures for hypersonic vehicles, 15th AIAA Space Planes and Hypersonic Systems and Technologies Conference, AIAA, 2008.

2 D. E. Glass, R. Dirling, H. Croop, T. J. Fry and G. J. Frank. Materials development for hypersonic flight vehicles, 14th AIAA/AHI Space Planes and Hypersonic Systems and Technologies Conference, AIAA, 2006.

3 S. M. Johnson, M. J. Gasch, D. Leiser and D. Stewart, Development of new TPS at NASA ames research center, 15th AIAA International Space Planes and Hypersonic Systems and Technologies Conference, AIAA, 2008. 
4 H. K. Tran, C. E. Johnson, D. J. Rasky, F. C. L. Hui, M. T. Hsu, T. Chen, Y. K. Chen, D. Paragas and L. Kobayashi. Phenolic impregnated carbon ablators (PICA) as thermal protection systems for discovery missions, NASA Technical Memorandum 110440, 1997.

5 H. K. Tran, C. E. Johnson, D. J. Rasky, F. C. L. Hui and M. T. Hsu. Silicone impregnated reusable ceramic ablators for mars follow-on missions, 31st AIAA Thermophysics Conference, AIAA, 1996.

6 S. A. Sepka and J. A. Samareh, Thermal protection system mass estimating relationships for blunt-body earth entry spacecraft, 45th AIAA Thermophysics Conference, AIAA AVIATION Forum, AIAA, 2015.

7 D. A. Stewart and D. B. Leiser. Toughened uni-piece fibrous reinforced oxidization-resistant composites. US Pat., US7381459B1, 2008.

8 D. A. Stewart, D. B. Leiser and R. R. Difiore. High efficiency tantalum-based ceramic composite structures. US Pat., US7767305B1, 2008.

9 D. A. Stewart and D. B. Leiser, Lightweight TUFROC TPS for hypersonic vehicles, 14th AIAA/AHI Space Planes and Hypersonic Systems and Technologies Conference, AIAA, 2006.

$10 \mathrm{~K}$. Skokova and B. Laub, Experimental evaluation of thermal protection materials for Titan aerocapture, 41st AIAA/ASME/ SAE/ASEE Joint Propulsion Conference \& Exhibit, AIAA, 2005.

11 I. J. Davies and R. D. Rawlings, Microstructural investigation of low-density carbon-carbon composites, J. Mater. Sci., 1994, 29, 338-344.

12 I. J. Davies and R. D. Rawlings, Mechanical properties in compression of low density carbon/carbon composites, Composites, 1994, 25, 229-236.

13 C. Liu, J. C. Han, X. H. Zhang, C. Q. Hong and S. Y. Du, Lightweight carbon-bonded carbon fiber composites prepared by pressure filtration technique, Carbon, 2013, 59, 547-554.

14 R. I. Baxter, R. D. Rawlings, N. Iwashita and Y. Sawada, Effect of chemical vapor infiltration on erosion and thermal properties of porous carbon/carbon composite thermal insulation, Carbon, 2000, 38, 441-449.

15 S. A. Kolesnikov and G. A. Kravetskii, Refractory structures made of low-weight carbon-bonded carbon-fiber-reinforced composites, Refract. Ind. Ceram., 2007, 48, 223-226.

16 S. M. Jonson, M. J. Gasch, D. Leiser, D. Stewart, M. Stackpoole and J. Thornton, Development of New TPS at NASA Ames Research Center, 15th AIAA, AIAA, Dayton, Ohio, 2008.

17 B. Helber, O. Chazot, A. Hubin and T. Magin, Microstructure and gas surface interaction studies of a low-density carbonbonded carbon fiber composite in atmospheric reentry plasmas, Composites, Part A, 2015, 72, 96-107.

18 Y. Zhang, Z. X. Lu, Z. Y. Yang, D. H. Zhang, J. J. Shi, Z. S. Yuan and Q. Liu, Compression behaviors of carbon-bonded carbon fiber composites: Experimental and numerical investigations, Carbon, 2017, 116, 398-408.

19 B. S. Xu, S. B. Zhou, C. Q. Hong, J. C. Han and X. H. Zhang, Mechanical enhancement of lightweight $\mathrm{ZrB}_{2}$-modified carbon-bonded carbon fiber composites with self grown carbon nanotubes, Carbon, 2016, 102, 487-493.

20 X. H. Zhang, B. S. Xu, C. Q. Hong, J. C. Han, F. X. Qin, W. B. Han, H. M. Cheng, C. Liu and R. J. He, Carbonbonded carbon fiber composites containing uniformly distributed silicon carbide, RSC Adv., 2014, 4, 6591-6596.

21 X. H. Xu, B. S. Xu, C. Q. Hong and D. Hui, Effect of pyrolytic carbon interface thickness on microstructure and mechanical properties of lightweight zirconium boride modified carbon-bonded carbon fiber composites, Composites, Part B, 2016, 96, 305-311.

22 J. Li, J. J. Sha, J. X. Dai, Z. Z. Lv, J. Q. Shao, S. H. Wang and Z. F. Zhang, Fabrication and characterization of carbonbonded carbon fiber composites with in situ grown SiC nanowires, Carbon, 2017, 118, 148-155.

23 M. Niu, H. J. Wang, J. B. Wen and X. Fang, Preparation and anti-oxidation properties of $\mathrm{Si}(\mathrm{O}) \mathrm{C}$ coated carbon-bonded carbon fiber composites, RSC Adv., 2015, 5, 52347-52354.

24 B. Du, C. Q. Hong, S. B. Zhou, C. Liu and X. H. Zhang, Multicomposition coating for oxidation protection of modified carbon-bonded carbon fiber composites, J. Eur. Ceram. Soc., 2016, 36, 3303-3310.

25 B. S. Xu, R. J. He, C. Q. Hong, Y. B. Ma, W. B. Wen, H. M. Li, T. B. Cheng, D. N. Fang and Y. Z. Yang, Ablation behavior and mechanism of double-layer $\mathrm{ZrB}_{2}$-based ceramic coating for lightweight carbon-bonded carbon fiber composites under oxyacetylene flame at elevate temperature, J. Alloys Compd., 2017, 702, 551-560.

26 M. Niu, H. J. Wang, L. Su, D. H. Zhang b and J. J. Shi, Fabrication and properties of lightweight SiOC modified carbon-bonded carbon fiber composites, Ceram. Interfaces, 2016, 42, 10614-10618.

27 L. Xue, Z. A. Su, X. Yang, D. Huang, T. Yin, C. X. Liu and Q. Z. Huang, Microstructure and ablation behavior of $\mathrm{C} / \mathrm{C}-$ HfC composites prepared by precursor infiltration and pyrolysis, Corros. Sci., 2015, 94, 165-170.

28 L. Luo, Y. G. Wang, L. Y. Duan, L. P. Liu and G. L. Wang, Ablation behavior of $\mathrm{C} / \mathrm{SiC}-\mathrm{HfC}$ composites in the plasma wind tunnel, J. Eur. Ceram. Soc., 2016, 36, 3801-3807.

29 F. Panerai, B. Helber, O. Chazot and M. Balat-Pichelin, Surface temperature jump beyond active oxidation of carbon/silicon carbide composites in extreme aerothermal conditions, Carbon, 2014, 71, 102-119.

30 Y. G. Wang, W. Liu, L. F. Cheng and L. T. Zhang, Preparation and properties of $2 \mathrm{D} \mathrm{C} / \mathrm{ZrB}_{2}-\mathrm{SiC}$ ultra-high temperature ceramic composites, Mater. Sci. Eng. A, 2009, 524, 129-133.

31 J. C. Han, P. Hu, X. H. Zhang, S. H. Meng and W. B. Han, Oxidation-resistant $\mathrm{ZrB}_{2}-\mathrm{SiC}$ composites at $2200{ }^{\circ} \mathrm{C}$, Compos. Sci. Technol., 2008, 68, 799-806.

32 C. R. Wang, J. M. Yang and W. Hoffman, Thermal stability of refractory carbide/boride composites, Mater. Chem. Phys., 2002, 74, 272-281.

33 F. Monteverde and A. Bellosi, The resistance to oxidation of an $\mathrm{HfB}_{2}-\mathrm{SiC}$ composite, J. Eur. Ceram. Soc., 2005, 25, 10251031. 
34 P. Lespadea, N. Richet and P. Goursat, Oxidation resistance of $\mathrm{HfB}_{2}-\mathrm{SiC}$ composites for protection of carbon-based materials, Acta Astronaut., 2007, 60, 858-864.

35 Y. Yang, K. Z. Li, Z. G. Zhao and H. J. Li, Ablation resistance of HfC-SiC coating prepared by supersonic atmospheric plasma spraying for SiC-coated C/C composites, Ceram. Int., 2016, 42, 4768-4774.

36 W. B. Han, P. Hu, X. H. Zhang, J. C. Han and S. H. Meng, High temperature oxidation at $1900{ }^{\circ} \mathrm{C}$ of $\mathrm{ZrB}_{2}-x \mathrm{SiC}$ ultrahigh temperature ceramic composites, J. Am. Ceram. Soc., 2008, 91, 3328-3334.
37 R. T. Shisode, S. R. Suryawanshi, C. D. Mistari, D. J. Late and M. A. More, Enhanced Field Emission Characteristics of a 3D Hierarchical $\mathrm{HfO}_{2}-\mathrm{ZnO}$ Heteroarchitecture, ChemistrySelect, 2017, 2, 2305-2310.

38 A. B. Phatangare, S. D. Dhole, S. S. Dahiwale, V. L. Mathe, S. V. Bhoraskar, D. J. Late and V. N. Bhoraskar, Surface chemical bonds, surface-enhanced Raman scattering, and dielectric constant of $\mathrm{SiO}_{2}$ nanospheres in situ decorated with Ag-nanoparticles by electron-irradiation, J. Appl. Phys., 2016, 120, 234901. 